\title{
Correction to: Hirschsprung disease and other gastrointestinal motility disorders in patients with CCHS
}

\author{
Keshawadhana Balakrishnan ${ }^{1,2}$ - Iris A. Perez ${ }^{3,4}$. Thomas G. Keens ${ }^{3,4}$ - Anita Sicolo ${ }^{3,4}$ - Jaya Punati ${ }^{3,4}$. \\ Tanaz Danialifar ${ }^{3,4}$
}

Published online: 5 January 2021

(C) Springer-Verlag GmbH Germany, part of Springer Nature 2021

\section{Correction to: European Journal of Pediatrics https://doi.org/10.1007/s00431-020-03848-5}

The authors regrets that the original version of the above article contained an error in a patient's mutation analysis. In their original manuscript, they stated that "G428A" was a novel PHOX2B mutation; however the mutation had been incorrectly reported by the laboratory. The correct mutation for that subject is "A428G".

The original article remained unchanged.

Publisher's note Springer Nature remains neutral with regard to jurisdictional claims in published maps and institutional affiliations.

The online version of the original article can be found at https:/doi.org/ $10.1007 / \mathrm{s} 00431-020-03848-5$

Tanaz Danialifar

tdanialifar@chla.usc.edu

Keshawadhana Balakrishnan

kxbalakr@texaschildrens.org

Iris A. Perez

IaPerez@chla.usc.edu

Thomas G. Keens

tkeens@chla.usc.edu

Anita Sicolo

asicolo@chla.usc.edu
Jaya Punati

jpunati@chla.usc.edu

1 Texas Children's Hospital, Houston, TX, USA

2 Baylor College of Medicine, Houston, TX, USA

3 Children's Hospital Los Angeles, 4650 Sunset Boulevard, MS 78, Los Angeles, CA 90027, USA

4 Keck School of Medicine of USC, Los Angeles, CA, USA 